\title{
IMPLICAC̣̃̃ES METODOLÓGICAS DO PROCESSO DE FORMAC̣ÃO DO LEITOR E DO PRODUTOR DE TEXTOS NA ESCOLA
}

\author{
Mary Elizabeth Cerutti Rizzatti*
}

\begin{abstract}
RESUMO: Este artigo focaliza a atuação do professor na formação do leitor e do produtor de textos no início da escolarização, discutindo, à luz de princípios teóricos da Lingüística Textual e das ciências cognitivas, implicações metodológicas que parecem relevantes na instrumentalização da capacidade discente para os atos de ler e de produzir textos de modo proficiente. Trata-se de uma reflexão que considera dados coletados junto a educadores infantis e professores de séries iniciais, pós-graduandos em Educação, em uma análise que topicaliza atividades de interpretação de texto e atividades de produção textual. O objetivo do estudo é relacionar habilidades docentes de leitura e escrita, opções metodológicas no trato com essas questões e maiores ou menores possibilidades de desenvolvimento de tais habilidades nos alunos nesses níveis de ensino.
\end{abstract}

Palavras-chave: Leitura; Produção Textual; Metodologia

\section{METHODOLOGICAL IMPLICATIONS OF THE PROCESS OF READERS' AND TEXT PRODUCERS' EDUCATION AT SCHOOL}

ABSTRACT: This study focuses on the performance/practice of the teacher in the education of readers and text producers at early schooling. In the light of the theoretical principles derived from textual linguistics and cognitive sciences, this article discusses methodological implications that seem relevant for promoting children who can both read and produce texts proficiently. The research data was collected from teachers who work with early schooling as well as from graduate students. The data analysis comprised both text comprehension and production. The objective was to relate the teachers' methodological action and the possibility of developing reading and writing abilities in early schoolchildren.

Keywords: Reading; Text Production; Methodology

* Professora do Departamento de Língua e Literatura Vernáculas da Universidade Federal de Santa Catarina. E-mail: maryeli@intercorp.com.br 


\section{INTRODUÇÃO}

Convivemos costumeiramente com duas clássicas queixas escolares; a primeira delas focada nos alunos: "Os alunos têm problemas de interpretação de texto". A segunda, bastante disseminada, na voz de alunos e professores: "Eu sei o que quero dizer, mas não consigo colocar no papel". Ambas as queixas, se consideradas à luz dos tantos anos de escolarização que constituem o universo educacional no Brasil e se tomadas sob a égide de que todas as disciplinas de estudo e todas as áreas do pensamento humano, em um país de língua portuguesa como o Brasil, necessariamente se processam nesse idioma, requerendo, portanto, leitura e produção textual intensas em língua portuguesa, fazem-nos questionar como é possível que haja tantos cidadãos escolarizados se, ao que parece, a incidência de problemas de interpretação e de colocação das idéias no papel é assim significativa.

Kleiman (2001) denuncia, de modo enfático, a forma como a escola vem lidando equivocadamente com a leitura e pontua, como possível causa-mor, a falta de formação teórica em leitura por parte dos professores. Já Foucambert (1997) menciona pesquisas realizadas na Europa que mostram os baixos níveis de leitura dos professores, o que parece não ser diferente no Brasil. Ambos são convergentes ao questionar como professores que não são leitores podem formar alunos leitores.

Minha experiência, ao longo dos últimos anos, com as disciplinas de Produção Textual, Alfabetização e Letramento e Metodologia de Ensino da Língua Portuguesa facultou-me conviver com um grupo expressivo de pós-graduandos formados em Pedagogia; aqui, refiro-me particularmente a um grupo de 250 alunos de diferentes turmas de pósgraduandos em Educação, todos pedagogos. Uma das primeiras perguntas que tenho feito na docência com tais disciplinas, e que mantive nesse grupo, é: "quantos livros de sua área de atuação profissional você leu neste ano?" As respostas sempre são precedidas por constrangedores silêncios, de janeiro a dezembro. De início, as obras citadas, em sua maioria, tendem a passar ao largo da pergunta que faço, já que são referidos títulos de auto-ajuda, literatura espírita ou obras comerciais em voga no momento. Nesse grupo, pude registrar um número de dezoito professores que estavam lendo obras de sua área de atuação por ocasião do desenvolvimento da disciplina.

A pergunta subseqüente que tenho feito, e que mantive nas turmas a que pertenciam tais alunos, é: "quantos livros de sua área de atuação você comprou neste ano?” Nesse caso, as respostas são ainda 
mais reticentes. Nas turmas a que pertenciam tais alunos, encontrei cinco profissionais que referiram compra recente de obras desse tipo. Aliás, suas dificuldades para referir títulos, autores e para evidenciar conhecimento sobre editoras que publicam materiais educacionais de qualidade parecem preocupantemente expressivas.

A constatação dessa realidade tem sido ratificada em diferentes pólos de assessoria nos quais tenho podido estabelecer contato com educadores infantis e com professores de séries iniciais. Isso me faz referir novamente Kleiman (2001) e sua preocupação com a formação teórica em leitura por parte dos professores; afinal, ler obras de sua área de atuação, em se tratando de pedagogos que atuam nas primeiras séries do processo de escolarização, ${ }^{1}$ parece implicar necessariamente ler sobre leitura e ler sobre escrita, afinal, nesse nível dá-se a consolidação da capacidade de leitura - decodificação - que, por sua vez, é parte da atividade de leitura - construção de sentidos (MORAIS, 1996), habilidades embrionárias nesses anos, sem mencionar que os alunos² são apresentados a e se familiarizam com o ato de escrever nessas séries.

Aqui, vale mencionar Vygotsky (1956/2000), para quem mediar a formação de uma habilidade em outrem supõe tê-la desenvolvido preliminarmente em si mesmo. Assim, professores que não são leitores teriam condições de mediar a formação de leitores? E mais: não sendo leitores, tais professores seriam efetivamente proficientes produtores de texto? E, não o sendo, poderiam formar produtores de texto?

Este estudo se debruça sobre essas questões, ainda que o faça tendo como mote o viés metodológico, isso porque, pela atividade proposta em classe a seus alunos, pelo professor, parece ser possível depreender suas concepções sobre leitura e produção textual, as quais, por sua vez, em nossa compreensão, evidenciam, em grande medida, seu preparo teórico e prático nessas áreas. O texto estrutura-se em duas seções, a primeira delas focaliza a leitura, tentando refletir sobre a queixa clássica "Os alunos têm problemas de interpretação de textos"; a segunda seção, por sua vez, enfoca a produção textual, por meio de outra entre as queixas clássicas: "Eu sei o que quero dizer, mas não consigo colocar no papel".

Trata-se de uma abordagem qualitativa, que analisa propostas de atividades de interpretação de texto apresentadas por esses 250 pósgraduandos, depreendendo desse corpus categorias de análise com base nas quais é focalizada tal atividade de interpretação nesse nível de escolaridade. As discussões sobre produção textual circunscrevem-se à performance dos 
próprios alunos, pautando-se em anotações de diário de campo que realizei por ocasião das aulas ministradas nos cursos já aludidos.

\section{Uma reflexão sobre a queixa:}

\section{"Os alunos têm problemas de interpretação de textos"}

Discutir interpretação de textos tem-se constituído, nos últimos anos, uma questão de funcionalidade controvertida. $\mathrm{O}$ ambiente escolar historicamente registra queixas em relação a tal questão sem, ao que parece, ter havido avanços substanciais nesse campo. Se considerarmos o boom de Literatura Infantil registrado, sobretudo, nas décadas de 1970 e 1980, seria de esperar que a capacidade de construir sentidos do material lido houvesse sido igualmente potencializada. Afinal, se esse processo se desenvolveu, seguramente foi por conta de ter havido leitores capazes de construir sentidos dos materiais lidos, isso sem mencionar o surgimento, a partir da década de 1990, de inúmeros outros recursos de leitura, a exemplo daqueles advindos das tecnologias da informação.

Os "problemas" de interpretação de texto, no entanto, persistem na cantilena dos corredores escolares e, a nosso ver, precisam ser renomeados, talvez reconceitualizados. Na verdade, em nosso entendimento, tais "problemas" tanto quanto os problemas de "não conseguir colocar as idéias no papel" devem-se, em boa porção, ao fato de que a postura metodológica clássica da escola tem tomado como quatro atividades - leitura, interpretação, redação e gramática - o que, efetivamente, seriam apenas duas: leitura e produção textual.

Livros didáticos e planos de ensino docentes, quando focados no desenvolvimento de habilidades de Língua Portuguesa como disciplina de estudo, tendem a dividir em quatro momentos a atividade docente: primeiramente, um texto é apresentado ao aluno para leitura; seguem-se a isso questões relacionadas a tal texto; posteriormente, há exercícios gramaticais e, por fim, uma atividade de produção textual/redação/ composição. ${ }^{3}$ Esse tipo de abordagem, entendemos, tem comprometido a compreensão de que só se fazem perguntas sobre um texto com a finalidade de mediar a construção dos sentidos desse mesmo texto. ${ }^{4}$ Do mesmo modo, entendemos que só se realizam exercícios gramaticais para que o sujeito possa se valer do conhecimento sobre a estrutura de seu idioma por ocasião da leitura e, sobretudo, em produções textuais orais ou escritas.

Em relação a essa última questão, nossa experiência tem mostrado que, não obstante eventuais avanços na compreensão das 
implicações de abordagem da gramática explícita em séries iniciais, o que atribuímos às infinitas discussões ${ }^{5}$ que tem havido nesse campo, sobretudo a partir da década de 1980, bem como à salvaguarda dos Parâmetros Curriculares Nacionais de Língua Portuguesa, os quais registram que "não se deve sobrecarregar os alunos com um palavreado sem função, justificado exclusivamente pela tradição de ensiná-lo" (BRASIL, 1997, p. 90), parece grassar, ainda, entre os professores com os quais temos tido contato a dificuldade de compreender que a explicitação de informações sobre a estrutura gramatical da língua portuguesa, em qualquer um de seus níveis, fonologia, morfologia, sintaxe e semântica, só se justifica se facultar ao aprendiz maior lucidez sobre essa estrutura por ocasião do ato de ler ou por ocasião de suas produções textuais escritas e orais que demandem o uso da variedade padrão. ${ }^{6}$

Assim, temos observado, nas escolas, por exemplo, exercitação exaustiva de plurais concomitantemente à convivência com produções escritas nas quais abundam problemas ${ }^{7}$ no uso desses mesmos plurais. Outro exemplo recorrente a que temos tido acesso é a flexão verbal. Ainda que muitos profissionais, principalmente na $4^{a}$ série, insistam em flexionar verbos em seus tempos e modos, são comuns, em produções escritas, dificuldades no uso dessas mesmas flexões na variedade padrão. Inferimos que incidências como essas decorrem (também ou principalmente) da dificuldade de associar abordagem gramatical explícita e uso efetivo do conhecimento decorrente dessa abordagem.

Aludimos, anteriormente, à prevalência, na escola, de quatro atividades que, em nossa compreensão, seriam apenas duas, porque concebemos que atividades de interpretação são desdobramentos da atividade de leitura e alimentadoras da atividade de escrita; e atividades de abordagem gramatical são facilitadoras da atividade de leitura e desdobramentos da atividade de produção textual e, como tal, precisam se dar no ir-e-vir do texto na interlocução entre aluno e professor. Em nosso entendimento, enquanto a inter-relação entre essas atividades não estiver clara para o professor, persistirá sua abordagem dissociada, pro forma, respondendo a posturas cristalizadas na escola, as quais se consolidam como parte de um ritual sobre o qual não se dá um processo de reflexão efetivo.

Kleiman (2001), ao criticar posturas equivocadas da escola com relação à leitura, menciona insistentemente a forma como se dá a interpretação dos textos. Nessa crítica, aponta perguntas sobre textos que requerem apenas respostas localizadoras; perguntas que objetivam elicitar 
itens de conhecimento gramatical; perguntas que têm resposta autoritária e previamente constituída; perguntas que elidem a voz do autor em favor da voz opinativa do aluno. Sua crítica é endereçada também ao método de abordagem da leitura, o qual, via de regra, contempla os mesmos passos invariavelmente, partindo da motivação do aluno até as perguntas sobre o texto, passando pela leitura silenciosa, leitura em voz alta, etc. A ausência de reflexão sobre a viabilidade de cada qual desses itens do percurso metodológico clássico parece fato na escola, a despeito de todas as discussões sobre gênero textual (KOCH, 2003 e 2004a; MARCUSCHI, 1983; BRAIT, 2001, por exemplo), advindas dos estudos precursores de Bakhtin [1979], (2003), discussões que fazem ver a variabilidade dos usos da linguagem, decorrentes de contextualizações sociais diversas.

A diversidade de gêneros, por via de conseqüência, requer da escola flexibilidade metodológica na abordagem textual, de forma a dar conta das demandas de cada qual desses gêneros, segundo suas especificidades formais e segundo, por exemplo, correlações entre intencionalidade/aceitabilidade/situacionalidade, fatores propostos por Beaugrande e Dressler, (1983) e Beaugrande (1997). Sob a ótica desses autores, intencionalidade corresponde aos diversos modos como os sujeitos usam os textos para levar a termo suas intenções comunicativas, mobilizando recursos adequados para tal. Já aceitabilidade, contraparte da intencionalidade, implica a forma como o interlocutor participa do processo de construção de sentidos, o que remete aos estudos do pragmatista Grice (1975) e suas referências sobre a necessidade de o produtor do texto observar a verdade conceitual, a suficiência de dados, a clareza formal e a relevância de conteúdo para que possa contar com a cooperação do interlocutor. A situacionalidade, a seu turno, ainda segundo Beaugrande e Dressler (1983) e Beaugrande (1997), evoca a adequação do texto à situação sociocomunicativa. A correlação entre esses conceitos, paralelamente ao conceito de gênero textual - para referir apenas algumas implicações de textualidade/textualização -, exige da escola contemporânea ressignificação de suas posturas na abordagem dos textos por ocasião da formação do leitor.

Essa lacuna na compreensão docente sobre as implicações do ato de ler na contemporaneidade parece legitimar a reprodução do rito metodológico sacralizado a que se refere Kleiman (2001). Esse rito, em nossa compreensão, é responsável, em grande medida, por perpetuar a dissociação entre interpretação de texto e atividade de leitura. Logo, fazer perguntas parece ser apenas parte do rito consagrado - uma entre quatro 
instâncias (leitura, interpretação, produção textual e gramática) com idêntica hierarquia de abordagem e independência - e não um exercício derivado de efetiva reflexão docente sobre quais aspectos precisam ser focalizados em cada texto específico para mediar a formação do leitor proficiente de tal texto; ou seja, a interpretação não parece estar a serviço da leitura proficiente e nem ser alimentadora da produção textual.

Proceder à reflexão aludida no parágrafo anterior exigiria do professor, preliminarmente, ser leitor de fato, capaz de fazer a leitura do texto que apresentará aos alunos e de se debruçar sobre a construção dos sentidos desse texto, de modo a antever eventuais óbices na leitura do aluno. Concebemos ser essa atividade preliminar do professor o ato que determinará o tipo e a quantidade de perguntas a serem feitas sobre cada qual dos textos, em detrimento da postura ritualizada de proceder a perguntas estereotipadas, independentemente das particularidades formais e conceituais de cada um dos textos levados para a classe. Fazer perguntas, enfim, é atividade a serviço da construção de sentidos; logo, é o professor-leitor que, ao se defrontar com o texto, dele depreenderá as perguntas que lhe cabe fazer para mediar a construção dos sentidos por parte dos alunos na situação sociocomunicativa específica de uma aula em particular.

Reflitamos sobre essas questões a partir de propostas de leitura levadas a termo por professores com os quais temos tido contato. Tais propostas são decorrentes de uma atividade de avaliação, requisito para conclusão da disciplina Metodologia de Ensino da Língua Portuguesa, em curso de pós-graduação lato sensu em Educação. Solicitamos aos professores que escolhessem um texto que julgassem adequado para leitura de seus alunos de séries iniciais - ou para ser lido para as crianças, no caso dos educadores infantis - e propusessem questões que, em seu entendimento, contribuiriam para focalizar a atenção do aluno, objetivando favorecer a construção dos sentidos do texto lido e objetivando a apropriação de novos elementos formais e conceituais potencialmente úteis em escritos futuros e/ou para compreensão das funções da escrita na sociedade.

Aludiremos aqui a apenas algumas entre as propostas apresentadas, dada a necessária brevidade do artigo. Todos os professores cujas propostas serão referidas são pedagogos de formação, já atuantes em escolas com classes de educação infantil ou séries iniciais nos sistemas públicos de ensino do estado de Santa Catarina. Os exemplos foram selecionados entre inúmeros trabalhos de avaliação, tendo como critério o 
conteúdo requerido nas respostas às questões apresentadas, o que organizamos em categorias de análise explicitadas nas subseções que seguem.

\title{
1.1. Propostas que denegam o conteúdo textual em favor de correlatos temáticos
}

Uma das maiores incidências que temos observado nas propostas analisadas é o que vamos chamar aqui de priorização de correlatos temáticos. Tendo sido convidados a fazer perguntas que favoreceriam a compreensão do texto escolhido por eles para sua classe de alunos, muitos professores apresentaram o texto e procederam a perguntas focalizando elementos externos do texto, embora suscitados pelo tema. Kleiman (2001, p. 26) denuncia, em seus estudos, esse tipo de comportamento docente que temos observado à exaustão e que exemplificamos a seguir.

\author{
Proposta 1 - Texto 1 \\ "O museu" (Pedro Bloch) \\ A menina tinha subido para Petrópolis. Levaram-na a visitar o Museu \\ Imperial. Ficou empolgada com tudo o que viu e, mais tarde, contou ao \\ irmão: \\ - Sabe? Eu fui visitar a casa de D. Pedro. \\ - Foi, é? \\ - Fui. É uma casa bonita, toda limpinha, com uma coroa, um manto, uma \\ bengala cheia de brilhantes. \\ O menino explica, depois de ouvir por alguns minutos a irmã: \\ - Mas você fala como se D. Pedro estivesse vivo. D. Pedro já morreu, boba! \\ - Morreu, é? \\ - Morreu - confirma o irmão. \\ E ela: \\ - Só se foi de tanto encerar aquele chão!
}

\section{Proposta 1 - Questões de interpretação}

1. O Museu Imperial é uma das principais atrações turísticas da cidade de Petrópolis, no estado do Rio de Janeiro. Antes de ser transformado em museu, esse palácio era a residência da família de D. Pedro II. Procure saber qual é o museu mais importante da sua cidade e conte a história dele.

2. Para que servem os museus?

3. Cite alguns objetos que podem ser encontrados em museus.

4. A menina foi a Petrópolis só para visitar o museu. Cite outros lugares de uma cidade que, em sua opinião, podem ser atrações turísticas.

5. Se você fosse passear com um amigo que está visitando a sua cidade pela primeira vez, quais seriam os locais que você escolheria para levá-lo?

6. Um museu pode guardar objetos que lembrem momentos importantes da história de um país, de uma cidade ou até mesmo de uma família. Procure em sua casa fotografias ou objetos que lembrem algum momento feliz de sua 
família. Traga-os para a escola e conte a história de cada um deles para seus colegas.

Parece evidente, nas seis questões propostas, o foco no tema "museu" em detrimento do foco no conteúdo do texto em si mesmo. As questões "saem do texto" e focam itens culturais, interessantes, é claro, para o enriquecimento do conhecimento de mundo dos alunos, mas alheios ao conteúdo do texto em si mesmo. O texto parece ter sido escolhido apenas como mote para tratar de museus, o que seguramente é iniciativa válida, um dos possíveis tipos de leitura, como adverte Geraldi (2001), mas, nesse caso, foge à proposta da atividade, que era apresentar questões que facultassem a compreensão do conteúdo do texto. Sobre tal compreensão, Koch (2004b) remete à importância do foco na intenção. Ainda que focalize a oralidade, entendemos que o conteúdo que segue é passível de extensão para o trato da proficiência em leitura.

Já que cada enunciação pode ter uma multiplicidade de significações, visto que as intenções do falante ao produzir um enunciado podem ser as mais variadas, não teria sentido atribuir-lhe uma interpretação única e verdadeira. O conceito de intenção é, assim, fundamental para a concepção da linguagem como atividade convencional: toda atividade de interpretação presente no cotidiano da linguagem fundamenta-se na suposição de que quem fala tem certas intenções, ao comunicar-se. Compreender uma enunciação, nesse sentido, é apreender essas intenções. A noção de intenção não tem, aqui, nenhuma realidade psicológica: ela é puramente lingüística, determinada pelo sentido do enunciado, portanto lingüisticamente constituída. $(\mathrm{KOCH}, 2004 \mathrm{~b}, \mathrm{p}$. 22)

Não advogamos, obviamente, em favor das interpretações únicas; aliás, Kleiman (2001) as condena, entendendo-as como autoritárias. Advogamos em favor do que Koch (2004b) sugere: uma compreensão que se aproxime, o mais efetivamente possível, das supostas intenções do autor. Compreendemos que - mesmo não havendo respostas únicas capazes de dar conta das intenções dos autores, como adverte Koch, dado que o ato de ler tem a ver também com as intenções dos leitores, como lembra Kleiman - ao educador compete discutir o conteúdo do texto, antes de transcender para lidar com temas a ele correlatos.

Paulo Freire (1982) recomenda que o aluno precisa ser preparado para se tornar sujeito do ato de ler. Para tanto, importa a compreensão do que consiste tal ato de ler; caso contrário, corremos o risco de proposições que tangenciam esse ato, a exemplo da abordagem 
que veiculamos anteriormente com base no texto "Museu". Morais (1996), ainda que partidário de uma visão estrita de leitura, potencialmente contrária a Freire, descreve o ato de ler citando quatro diferentes implicações: capacidade de leitura, objetivo de leitura, performance em leitura e atividade de leitura. Para ele, a capacidade de leitura é específica da atividade de leitura, não sendo parte de outras atividades quaisquer, enquanto o objetivo da leitura é a compreensão ou a fruição, e a performance é o grau de sucesso da atividade de leitura. Já a atividade de leitura propriamente dita é "o conjunto de eventos que se passam no cérebro e no sistema cognitivo que o cérebro suporta, assim como nos órgãos sensoriais e motores" (MORAIS, 1996, p. 112).

Se o objetivo da leitura é a compreensão, ${ }^{8}$ compete ao professor, incumbido da formação do leitor, propor atividades que promovam essa mesma compreensão, o que deverá desencadear o conjunto de eventos que tem lugar no sistema cognitivo do sujeito por ocasião do ato de ler. Em nossa compreensão, ser sujeito do ato de ler, como propõe Freire (1982), ainda que o faça em uma dimensão bem mais ampla do que sugere o olhar cognitivista de Morais (1996), implica, preliminarmente, entender o conteúdo lido para se posicionar frente a ele na amplitude sóciohistórica e cultural do entorno. Logo, se o professor denega a interação sobre o conteúdo lido em favor do foco em temas correlatos a esse conteúdo, fica a possibilidade de tal conteúdo em si mesmo passar despercebido e não ser efetivamente compreendido pelo leitor, ainda que tal compreensão não deva, obviamente, ter configuração única e autoritária. Kleiman (2001) adverte para a importância da interação entre professor e aluno focando a leitura realizada, dado que de tal interação emerge, não raro, a construção efetiva de sentidos do texto.

Talvez a interação entre professor e alunos, por ocasião da leitura do texto "Museu", pudesse elicitar, por exemplo, o viés irônico do texto, tanto quanto socializar o conhecimento de mundo sobre a condição expressiva de brilho que caracteriza o chão daquele museu em especial, elementos, ao que parece, significativos para a leitura desse texto. Essas e outras tantas questões passíveis de depreensão por meio da leitura e de necessária focalização por ocasião da construção dos sentidos foram denegadas na proposta - e em inúmeras outras no universo dos 250 informantes - em favor da "saída" imediata do texto para o mundo; talvez tal saída nos permita inferir possíveis dificuldades no trato com o texto em si mesmo: seria mais fácil conduzir a discussão para temas correlatos, o que, em boa medida, descomprometeria o professor de uma leitura mais 
efetiva do material apresentado aos alunos? Ou essa saída traria implícita a suposição de que a construção de sentidos dá-se facilmente e prescinde da interação professor-aluno?

\subsection{Propostas que denegam o conteúdo do texto em favor de enfoques comportamentais}

Uma das questões que vêm nos chamando atenção no decurso deste trabalho com tais pós-graduandos é a prevalência de discussões, argumentações e justificações do senso comum na fala dos professores. No bojo desse conteúdo, inteiramente destituído de aporte teórico, parecem estar, hoje, muito fortemente marcados argumentos e preocupações relacionados à inclusão social, por exemplo - item relevante, a nosso ver, por ocasião da discussão de abordagens que tangenciam o texto para focar questões comportamentais.

A exemplo de outros tantos conceitos que ganham território no meio educacional, ${ }^{9}$ mas o fazem desacompanhados do aprofundamento teórico que naturalmente requerem, o conceito de educação inclusiva, no âmbito do que temos vivenciado na interação com esses professores, parece voz corrente, uma voz marcada por chavões e frases feitas. Isso tem se revelado sobremodo na interação com educadores infantis participantes desses cursos de pós-graduação, muitos deles ocupados no trato com os contos clássicos da Literatura Infantil. O conto "O patinho feio", de H. C. Andersen, é um dos textos que mais freqüentemente têm sido reféns ${ }^{10}$ dessa abordagem. Tomemos um exemplo de proposta para a Educação Infantil a partir desse conto, que dispensa transcrição aqui, dado o amplo conhecimento que se tem dele.

\section{Proposta 2 - Questões de interpretação (interação oral)}

Texto: "O patinho feio"

1. Você acha que os animaizinhos deveriam ter tratado assim o patinho?

2. Como devemos tratar os amiguinhos diferentes?

3. O que devemos fazer para acolher novos amiguinhos, diferentes de nós, que chegam à nossa escola?

4. Você já teve algum amiguinho diferente no lugar onde você mora? Como você o tratou?

5. Por que não devemos tratar mal pessoas que apresentam alguma diferença em relação a nós?

Entendemos explícita a preocupação dos educadores infantis proponentes dessa atividade com a inclusão social, com a formação humana. Ainda que sejam moralmente elevados tais propósitos, o fato de 
a atividade requerida constituir parte de uma aula de leitura, inserida nas discussões da disciplina de Metodologia do Ensino da Língua Portuguesa, aumenta nossa preocupação com a qualidade do leitor egresso de um processo sistemático de discussão que tenha tal configuração. Talvez o produto seja um cidadão muito bem-intencionado, mas possivelmente não um leitor competente.

Koch (2003, p. 48), com base em Heinemann e Viehweger, afirma que, para o processamento textual, concorrem três grandes sistemas de conhecimento: lingüístico, enciclopédico e interacional. Escreve a autora:

O conhecimento lingüístico compreende o conhecimento gramatical e o lexical, sendo o responsável pela articulação som-sentido. É ele o responsável, por exemplo, pela organização do material lingüístico na superfície textual, pelo uso dos meios coesivos que a língua nos põe à disposição para efetuar a remissão ou a seqüenciação textual, pela seleção lexical adequada ao tema e/ou aos modelos cognitivos ativados.

O conhecimento enciclopédico ou conhecimento de mundo é aquele que se encontra armazenado na memória de longo termo, também denominada semântica ou social.

O conhecimento sociointeracional é o conhecimento sobre as ações verbais, isto é, sobre as formas de inter-ação através da linguagem. Engloba o conhecimento do tipo ilocucional, comunicacional, metacomunicativo e superestrutural.

A consciência sobre essas implicações do processamento textual sugere que a atuação do professor precisa chamar a atenção do aluno, durante a interação no ato de ler, sobre questões que suscitem a ativação desses conhecimentos referidos por Koch (2003), o que, entendemos, remete à atividade de leitura de que trata Morais (1996). Caso, como nesta abordagem do conto "O patinho feio", a ação docente, também tangenciada, vise a posturas morais e comportamentais em detrimento do ato de ler efetivamente, o processamento textual seguramente não merecerá a exercitação devida.

Nesse conto de Andersen, narrativa que, segundo Coelho (1987), tem viés autobiográfico em razão das dificuldades de relacionamento familiar que o autor teria atravessado em sua infância, é, para nós, notória a presença de dois processos importantes: a distinção do grupo de origem e a identificação com o novo grupo. Por ocasião do processo de distinção do grupo de origem - motivado, nesse caso específico, por questões físico-estéticas objetos de rejeição grupal -, a personagem somente se evade do grupo quando sente a rejeição materna. Seu trans- 
curso rumo ao novo grupo prevê hiato suficiente para que sua caracterização efetiva se revele: tornou-se um cisne e foi identificado como tal pelos seus.

Em nossa compreensão, a ação docente, por ocasião da "contação" dessa história para crianças da Educação Infantil, precisa necessariamente chamar a atenção das crianças para esses dois grandes momentos e as particularidades de que se revestem. $\mathrm{O}$ conhecimento lingüístico precisa ser requerido em todo o percurso de discussão, desde a correlação lexical pato/cisne, implicada no texto. Já o conhecimento enciclopédico é item fundamental porque supõe a distinção entre filhote de pato/filhote de cisne; além de questões conceituais psicologicamente mais complexas, mas não menos lingüísticas, como rejeição e aceitação. Talvez, segundo a semiótica greimasiana (BARROS, 1997), a rejeição seria a disforia e a identificação, a euforia, mas isso implica enveredar por uma análise mais estrutural. Enfim, o conhecimento sociointeracional requereria do professor questões que focalizassem, por exemplo, a superestrutura do texto, tão rica nos contos clássicos; isso tudo, obviamente, em uma linguagem compatível com o universo infantil.

Em vez de proceder a uma interação que permitisse a elicitação dessas (e muitas outras) questões explicitadas e implicitadas no conteúdo textual, a opção dos educadores infantis, nessa segunda proposta, foi pela priorização da formação do cidadão, o que parece equivocado em razão de se tratar de uma proposta para a aula de leitura, cujo objetivo é a formação do leitor proficiente - no mais, possivelmente fosse uma iniciativa louvável colocar o foco na cidadania.

Esse tipo de comportamento tangencial, presente aqui e também na discussão da subseção anterior, tem-se revelado muito insistentemente no comportamento dos próprios professores quando lêem textos teóricos e têm de expô-los em uma discussão coletiva. Nossa experiência tem nos mostrado, de modo muito recorrente, que, quando esses professores são convidados a ler capítulos teóricos de obras que desenvolvem conteúdos da ementa da disciplina, a maioria absoluta deles - durante a socialização de sua compreensão - elide o registro sobre o conteúdo do texto e passa a discorrer sobre exemplos de sua vida profissional correlacionados ao tema.

Temos tido dificuldades de encontrar pós-graduandos que, em sua fala sobre o texto, informem o conteúdo lido para, a partir dele, veicular a sua voz, dialogando com o autor. A leitura, que deveria ser o processo dialógico de que tratam Bakhtin; Volochinov ([1929] 2002) e Ducrot 
(1972), termina por ser um monólogo; nesse caso, monólogo do leitor que, sem escutar o autor, fala sobre o tema monologicamente, terminando por afastar-se (e, não raro, contradizer) o conteúdo teórico veiculado no texto lido. Em monografias desses alunos, esse comportamento se repete, revelando leituras tangenciais, que, muitas vezes, colocam em risco a veracidade dos intertextos presentes nas citações diretas e indiretas de tais escritos. Parece-nos, enfim, que, tanto a prevalência de olhares temáticos correlatos ao texto (subseção 1.1) quanto a prevalência de enfoques comportamentais (subseção 1.2) são formas de tangenciar a reflexão sobre o texto, ricas em si mesmas, mas discutíveis como parte de uma aula de leitura.

\subsection{Propostas que denegam o conteúdo textual em favor da opinião do leitor}

Outro comportamento significativamente recorrente em nossa experiência com esse grupo de pós-graduandos é a proposta de atividades que elidem a vOz do autor em favor da voz opinativa do aluno. Essa forma de agir, como referimos na subseção anterior, revela-se de modo bastante efetivo no comportamento dos próprios pós-graduandos. Tomemos um exemplo desse tipo de postura, uma proposta para alunos de $3^{a}$ série.

\section{Proposta 3 - Texto 3}

\section{"Liga e Desliga" (Camila Franco)}

Era uma vez uma televisão que não saía da frente de um menino. Todo dia e toda hora, lá estava ela assistindo ao menino. Já não brincava mais com suas amigas televisões da rua.

Ficava lá na sala, sem trocar de canal. Era sempre o mesmo menino que ela via. A sua Mãetsubishi sempre dizia:

- Desliga esse menino, TV.

TV era seu apelido em casa. E TV, nada.

O seu Painasonic, quando chegava em casa, era mais energético. Ia até a sala e desligava o menino. Mas TV chorava em chuviscos e o senhor Painasonic acabava tendo que ligar o menino de novo.

Toda noite, TV queria ficar vendo o menino até tarde. Mas a Mãetsubishi dizia que isso não era bom, que hoje em dia os meninos passavam muitas cenas de violência, impróprias para catorze polegadas. E, depois, TV não desligava à noite de medo.

E lá ia TV pro seu quarto, desligar cedo, pensando no que ia passar amanhã no menino.

Um dia, o menino ganhou uma bola. E quando TV foi pra sala, logo depois do café da manhã (TV adorava vitamina de pilha com fusível), o menino já não estava mais lá.

TV ficou sem saber o que fazer. Estava completamente fora do ar. Ia assistir 
ao quê, agora? Foi até a janela e viu, ao vivo e em cores, o mundo, o menino jogando bola com outros meninos.

Naquela noite, TV pediu pro seu Painasonic mandar o menino pro conserto. Ele mandou, mas não adiantou nada. O técnico de meninos disse que aquele menino já não tinha mais conserto. A bola tinha sido uma interferência muito forte.

TV ficou inconsolável. Não ia mais poder assistir ao menino o dia inteiro. Só depois que o menino, imagine, parasse de jogar bola. Mas, de tanto esperar o final do jogo, também começou a brincar.

E não a brincar sozinha, mas com as outras televisões do bairro, que também estavam sem menino.

Elas brincavam de transmitir imagens. De emitir pessoas famosas. E de ligadesliga, liga-desliga.

Foi nessa época que TV acabou conhecendo TVzinha, uma televisão que era sua vizinha e em quem TV nunca tinha reparado. Claro, TV só tinha botões para o seu menino.

Agora todas as televisões vivem fazendo programas. Programa esportivo, programa infantil, até programa cultural.

E o menino, com a nova vida da TV, passou a brincar de outras coisas, além de jogar bola.

TV só assistia ao menino depois da lição e antes do banho. Ou então quando passava uma coisa muito incrível no menino. TV não era de ferro, não é?

\section{Proposta 3 - Questões de interpretação}

1. Você gostou do texto?

2. Você acha que é possível isso acontecer na realidade?

3. O que você faria se fosse a TV?

4. Você gosta de televisão? Assiste a muitos programas? Quais?

5. Você achou o final interessante? O que você mudaria no texto?

Todas as cinco questões trazem o pronome você, estando focadas na opinião do leitor. A despeito da riqueza do texto, visível na personificação da TV e na inversão de perspectivas em relação às personagens, a proposta das professoras circunscreveu-se a ouvir a voz opinativa das crianças, denegando o estranhamento que singulariza o texto. Essa opção seguramente redundará em discussões do senso comum sobre televisão, mazelas e benesses. De novo, Kleiman:

Uma outra prática que passa por leitura, que não é apenas decodificação, mas também torna a atividade dispensável, pois revela a mesma atitude de descaso em relação à voz do autor, dispensa a etapa de compreensão dessa voz, consiste em solicitar uma opinião dos alunos sobre o assunto logo após a leitura do texto, sem sequer ter discutido o assunto tal como ele é tratado pelo autor. (KLEIMAN, 2001, p. 23) 
Geraldi alerta para o necessário cuidado com a sobreposição de vozes ao escrever que a leitura é um processo

cuja trama toma as pontas dos fios do bordado tecido para tecer sempre o mesmo e outro bordado, pois as mãos que agora tecem trazem e traçam outra história. Não são mãos amarradas - se o fossem, a leitura seria reconhecimento de sentidos e não produção de sentidos; não são mãos livres que produzem o seu bordado apenas com os fios que trazem nas veias de sua história - se o fossem a leitura seria um outro bordado que se sobrepõe ao bordado que se lê, ocultando-o, apagando-o substituindo-o. (GERALDI, 1997, p.166. Grifo nosso)

Charolles (1978) e Grice (1975) são pródigos em reconhecer que o interlocutor coopera na construção dos sentidos do texto. Ler não é uma atividade passiva; ao contrário, o leitor se empenha para construir a coerência do texto, coerência entendida como eixo de sentido desse mesmo texto. Logo, a experiência do leitor, como advertem Kleiman (2001) e Koch (2003), é crucial e precisa ser requerida no ato de ler. Essa postura ativa, no entanto, não legitima, sob nenhum ponto de vista, suplantar a vOz do autor, vOz cuja compreensão essa cooperação do interlocutor busca alcançar.

Tal prática de prevalência opinativa preliminar, denegando a leitura de fato, a nosso ver, contribui para o que anteriormente mencionamos: a prevalência do senso comum nas discussões. Parece haver, entre os professores com quem temos convivido, uma tendência a posicionar-se e a argumentar sobre questões conceituais sem antes se cercarem do cuidado de conhecer mais efetivamente os conceitos que tematizam e sobre os quais se posicionam com falas feitas. Costumamos repetir, a exemplo do que reza o dito já de autoria coletiva, que somos, em grande medida, "construtivistas de orelha, vygotskyanos de orelha, marxistas de orelha", etc., ou seja, ouvimos falar sobre e passamos a fazer eloqüentes discursos, nos corredores da escola, sobre o que nem sempre conhecemos devidamente, porque não lemos nem mesmo a orelha das obras desses pensadores nas quais estão veiculados tais conceitos.

Agir assim parece compatível com o costume de apresentar textos aos alunos e, de imediato, priorizar suas opiniões em detrimento da discussão sobre o conteúdo textual. Opiniões parecem estar bem-cotadas no mercado da escola, enquanto domínio teórico e reflexão conceitual mostram-se em "baixa" na bolsa de valoração docente; mas, para opinar com propriedade, todos sabemos, importa conhecer. 


\subsection{Propostas que focam o conteúdo explícito em atividades de mapeamento do dito}

Os PCNs de Língua Portuguesa (1997) registram que ler transcende decodificar. Morais (1996), como já aludimos, compreende a decodificação - capacidade de leitura - como parte da atividade de leitura. Logo, ler não é sinônimo de mapear o que está posto no texto via processo de decodificação; isso é apenas uma implicação necessária ao ato de ler. "Formar um leitor competente supõe formar alguém que compreenda o que lê, que possa aprender a ler também o que não está escrito" (BRASIL, 1997, p. 54; grifo nosso). As atividades a que nos reportamos neste estudo são eloqüentes em apresentar propostas de prevalência absoluta de questões de respostas localizadoras. Mais uma vez, recorremos a Kleiman (2001, p. 20), para quem a leitura como decodificação é uma prática empobrecedora que dá lugar a leituras dispensáveis. Koch (2004b, p. 159), por sua vez, recomenda:

nas aulas de leitura é importante conscientizar o aprendiz da existência, em cada texto, de diversos níveis de significação. Isto é, cumpre mostrar-lhe que, além da significação explícita, existe toda uma gama de significações implícitas, muito mais sutis, diretamente ligadas à intencionalidade do produtor.

Nesse sentido, vale referir Ducrot (1972), ${ }^{11}$ para quem é possível identificar três formas de implícitos: baseados na enunciação, envolvendo subentendidos; baseados no enunciado, envolvendo inferências; e baseados no enunciado, envolvendo pressupostos. Koch (2004b, p. 27), em convergência com isso, alerta: "Não basta conhecer o significado literal das palavras ou sentenças de uma língua: é preciso saber reconhecer todos os seus empregos possíveis, que podem variar de acordo com as intenções do falante e as circunstâncias de sua produção". Isso não parece estar sendo considerado por muitos professores no encaminhamento da leitura em classe. O texto que segue é uma proposta para a $3^{a}$ série.

\section{Proposta 4 - Texto 4}

\section{"Chapeuzinho vermelho de raiva"}

(Samir Curi Meserani e M. Kato - adaptação)

- Senta aqui mais perto, Chapeuzinho. Fica aqui mais pertinho da vovó, fica.

- Mas, vovó, que olho vermelho... E grandão... Que que houve?

- Ah minha netinha, estes olhos estão assim de tanto olhar para você. Aliás, está queimada, hein?

- Rincão, vovó. Passei o fim de semana lá. A senhora não me leve a mal, não, mas a senhora está com um nariz tão grande, mas tão grande! Tá tão esquisi- 
to, vovó.

- Ora Chapéu. É a poluição. Desde que construíram estas indústrias aqui no bosque, é um Deus nos acuda. Fico o dia todo respirando este ar horrível. Chegue mais perto minha netinha, chegue.

- Mas em compensação, antes eu levava mais de duas horas para vir de casa até aqui e agora, com a estrada asfaltada, em menos de quinze minutos chego aqui com minha moto.

- Pois é, minha filha. E o que tem aí nesta cesta enorme?

- Puxa, ia me esquecendo, a mamãe mandou umas coisas para a senhora. Olha aí, margarina, maionese Hellmann's, Danone de frutas e até uns pacotinhos de sopa Knorr, mas é para a senhora comer um só por dia, viu. Lembra da outra vez que a senhora comeu tudo em um dia e passou mal?

- Se lembro, se lembro...

- Vovó, sem querer ser chata.

- Ora, diga.

- As orelhas. A orelha da senhora está tão grande. E, ainda por cima, peluda. Credo vovó!

- Ah, mas a culpada é você. São estes CD's malucos que você me deu. Onde já se viu fazer música desse tipo? Um horror! Você me desculpe, porque foi você que me deu, mas estas guitarras, é guitarra que se diz, não? Pois é, estas guitarras são muito barulhentas. Não há ouvido que agüente, minha filha. Música é do meu tempo. Aquilo sim, eu e seu finado avô, dançando valsa. Ah, esta juventude está perdida mesmo.

- Por falar em juventude, o cabelo da senhora está um "barato", hein? Todo desfiado e encaracolado. Que qué isso?

- Também tenho que entrar na moda, não é, minha filha? Ou você queria que eu fosse no shopping e no McDonald's de coque com vestido preto com bolinhas brancas?

Chapeuzinho pula para trás.

- E esta boca imensa???????

A avó pula da cama e coloca as mãos na cintura, brava.

- Escuta aqui, queridinha, você veio aqui hoje para me criticar, é?!

Proposta 4 - Questões de interpretação

1. Que perguntas Chapeuzinho fez à Vovó?

2. Qual foi a vantagem que Chapeuzinho teve depois que construíram as indústrias no bosque?

3. Por que o ar do bosque estava poluído?

4. Aonde a vovó ia aos domingos?

5. Quando Chapeuzinho ia visitar a vovó ela sempre levava uma cesta com comidas deliciosas. Chapeuzinho falou para vovó comer uma só por dia. Por quê?

6. O que, neste texto, é diferente da história tradicional?

Nesse texto, a riqueza intertextual com o conto clássico, os itens de modernidade, as particularidades interacionais entre a vovó e a meni- 
na, entre outros tantos aspectos interessantes, ficam secundarizados em nome de perguntas de respostas localizadoras.

Sabemos que o foco na educação da atenção seletiva exige do professor propor perguntas que requeiram reconstrução da linearidade explícita das narrativas, sobretudo com crianças pequenas que estão em processo de desenvolvimento dessa mesma atenção. Na proposição da atividade, no entanto, mantivemos claro o objetivo: questões para construir os sentidos do texto, o que exigia a aproximação das intenções do produtor, a exemplo do que recomenda Koch (2004b). Isso não parece ter acontecido nessa proposta e em inúmeras outras que continham também e/ou principalmente respostas localizadoras, mas apresentavam algumas questões que demandavam reflexão mais substantiva.

\subsection{Correlaç̃ões entre propositura de questões de interpretação e capacidade docente para interpretar textos: uma reflexão pontual}

Questão correlacional que observamos ao longo desse processo é a dificuldade revelada por grande parte desses professores para construir os sentidos dos textos que lêem, o que não se circunscreve a textos teóricos mais densos, mas se estende a textos mais breves e menos pretensiosos. Nessas incursões com a docência na disciplina em questão, temos apresentado aos professores o texto que segue, de Millôr Fernandes, em uma versão adaptada, objetivando a discussão dos sentidos. Tomemos o texto.

\section{“O acordo (À moda dos turcos)"}

Millôr Fernandes (Adaptação com fins didáticos.)

Um caçador se vestiu para caçar. Entrou na floresta fechada para procurar um animal que tivesse uma pele grossa para esquentar suas noites de inverno.* $\mathrm{E}$ procurava. Procurava, que procurava. Então, numa volta da floresta, encontrou um urso. Os dois se olharam. O caçador apavorado com o tamanho do animal. O animal apavorado com a arma do caçador. Mas foi o urso quem falou** primeiro.

- Que é que você está procurando?

- Eu - disse o caçador - procuro uma boa pele para me esquentar no inverno. E você?

- Eu - disse o urso - procuro algo para jantar, porque há três dias que não como.

E os dois se puseram a pensar. E foi de novo o urso quem falou primeiro:

- Olha, caçador, vamos entrar na toca e conversar lá dentro que é melhor.

Entraram. E dentro de meia hora, o urso tinha o seu jantar e, conseqüentemente, o caçador tinha o seu capote. 
*Esta história aconteceu há muitos séculos.

**Esta história é do tempo em que os animais falavam. Percebe-se?

Ao final da leitura, perguntamos aos professores: "O que vocês acham que aconteceu dentro da caverna"? Cerca de 20\% dos informantes aproximam-se da suposta intencionalidade do autor de informar que o urso havia comido o caçador. A maioria absoluta dos profissionais dessas turmas e das demais tende a insistir em argumentações sobre a possível existência de outros animais dentro da caverna, de modo a compatibilizar a vontade de ambas as personagens, sem dano a nenhuma delas. As hipóteses sobre o conteúdo de eventual conversa entre o caçador e o urso dentro da caverna têm sido bastante interessantes. Muitos pós-graduandos aludem ao fato de que o urso não fala, sem ter percebido a nota de rodapé e o tom irônico nela veiculado; outros pós-graduandos aludem ao termo "acordo", sem perceber o que está abaixo do título, entre parênteses.

Parece-nos, pois, evidente nessas situações - e elas têm se revelado recorrentes - a negligência no ato de ler. Seria esse comportamento decorrente da leitura sacádica de que tratam os cognitivistas ${ }^{12}$ - estaria ela atuando em desfavor da leitura nesses casos - ou estaríamos simplesmente diante de leitores desatentos? Quaisquer que venham a ser as respostas, há fortes indícios para crermos que profissionais com essa performance (MORAIS, 1996) em leitura possivelmente atuem em classe no sentido de requerer de seus alunos performance análoga. De novo Vygotsky (1956/2000) e a necessidade de ter desenvolvido em si mesmo uma habilidade antes de mediar tal desenvolvimento em outrem.

Voltemos a Ducrot (1972) para resgatar o texto de Millôr Fernandes. Parece haver, nesse texto, no enunciado, registros bastante indicativos da intencionalidade do autor. A expressão que Millôr coloca entre parênteses após o título leva a crer que, neste acordo específico, houve desequilíbrio em favor de uma das partes. As referências às iniciativas do urso, em detrimento da inércia do caçador, parecem indicar de quem foi a vantagem no acordo, mas, sobremodo, o advérbio "conseqüentemente", no parágrafo final, remete a uma relação de causa e conseqüência respectivamente entre ter o jantar e ter o agasalho.

A nosso ver, a habilidade aqui requerida é a capacidade de realizar inferências de que trata Ducrot (1972) e a ativação dos três tipos de conhecimento a que se refere Koch (2004b), o que não parece se revelar em grande número dos profissionais com quem convivemos no âmbito deste estudo - daí possivelmente ser essa uma das razões para as 
abordagens periféricas sugeridas nas subseções aqui registradas. Esse comportamento correlacional repete-se, em grande medida, quando o assunto é produção textual. Vamos a ele, em uma discussão mais abreviada.

\section{Uma reflexão sobre a queixa:}

\section{"Eu sei o que eu quero dizer, mas eu não consigo colocar no papel"}

A convivência com essa queixa, relacionada à produção textual escrita, data de muito tempo antes da experiência com as turmas aqui focalizadas, mas encontra nelas endosso efetivo e preocupante. "Saber o que dizer e não conseguir colocar no papel” supõe, em compreensão preliminar, dificuldade cognitiva de construção/organização da informação à luz da trajetória social, histórica e cultural empreendida pelo sujeito. Podemos inferir, a partir de estudos cognitivistas, que o processamento de saída da informação é linear, enquanto o processamento de entrada da informação não revela essa característica necessariamente. Ambos os processos, no entanto, ainda que se distingam sob esse ponto de vista, têm em comum sua necessária inserção em uma dimensão contextual historicamente situada, ou seja, não podem ser tomados na sua subjetividade psíquica sem a consideração de que têm, no meio social, sua fonte alimentadora/justificadora.

Ante a queixa sobre a dificuldade de organização da informação com vistas à produção textual, um possível lenitivo imediato seria a proposição de atividades de planejamento da escrita, de modo a organizar o processamento de saída da informação do sistema cognitivo, o que, em princípio, resolveria o problema objeto da queixa. Por que, no entanto, isso parece infrutífero? Entendemos que a inviabilidade de uma ação mecânico-comportamental como essa se deve, em grande medida, à necessária subjacência da construção sócio-histórica do sujeito como produtor de texto, o que demanda muito mais do que orientação procedimental.

Em nosso entendimento, assim, a questão não parece dever ser tão circunscrita. A queixa, concebemos, esconde em si mesma um aspecto que transcende o processamento de saída da informação por si só, para se situar também na informação propriamente dita e, sobremodo, no percurso interacional do qual ela deriva, ou seja, não se trataria exatamente de saber o que se tem a dizer e não conseguir externar, mas, em grande medida, de não saber ainda, de fato, o que dizer. Aqui, novamente, retomamos Beaugrande e Dressler (1983) e Beaugrande (1997) e o conceito de informatividade, bem como Grice (1975) e suas alusões à suficiência de dados. 
Vale retomar, ainda, Bakhtin (2003 [1979]) e Bakhtin; Volochinov ([1929] 2002) e suas discussões sobre a dimensão ideológica do dizer e sobre os usos sociais em que esse dizer se situa. Ainda que os autores priorizem o foco da atividade interlocutiva, parece-nos possível estender esses conceitos para o ato de produção textual.

O processamento de saída da informação, necessariamente situado sob o ponto de vista sócio-histórico, por ocasião da produção tex-tual só é possível, por razões lógicas, se preliminarmente tiver havido processamento cognitivo de entrada da informação, o que é marcado pela alteridade. Não podemos externar conteúdos que não detivermos internamente em nossa memória de longo termo e dos quais não nos tivermos apropriado sócio-historicamente; e, para tal, importa que tenha havido um input, por meio do sistema sensorial; um fatiamento da informação via memória de trabalho; um repositório do conhecimento ativado em estado de alerta na memória intermediária; e a estocagem na memória de longo termo (KLEIMAN, 2001), processamento que se consolida nas diferentes situações de uso da língua que motivam a ação social dos sujeitos. Trata-se de uma interação que implica input por via auditiva e visual sobremodo. No entanto, em nosso entendimento, a entrada de informação que efetivamente habilita o sujeito para o ato da escrita parece ser a visual, via leitura, uma apropriação conceitual e formal cuja construção de sentidos é perpassada pelo dialogismo. Ler é processo dialógico alimentador da escrita. Os PCNs - LP (BRASIL, 1997, p. 53) registram:

O trabalho com leitura tem como finalidade a formação de leitores competentes e, conseqüentemente, a formação de escritores, pois a possibilidade de produzir textos eficazes tem sua origem na prática de leitura, espaço de construção da intertextualidade e fonte de referências modelizadoras. A leitura, por um lado, nos fornece matéria-prima para a escrita: o que escrever. Por outro, contribui para a constituição de modelos: como escrever.

$\mathrm{O}$ ato de escrever demanda conteúdos a serem escritos, o que remete à necessidade de um nível informacional que, a exemplo do que registram Beaugrande e Dressler (1983) e Beaugrande (1997), alterne ocorrências de processamento imediato com ocorrências de processamento mais trabalhoso, dado que um texto menos previsível é mais informativo, porque sua recepção, ainda que mais trabalhosa, é mais interessante e envolvente na maioria das vezes. É notório que a avaliação desses níveis é variável tanto quanto são variáveis os interlocutores.

A informatividade é um conceito que remete à distribuição da informação no texto tanto quanto ao grau de previsibilidade/redundância 
dessa informação, grau cujo dimensionamento é passível de ser avaliado tão-somente na concretude de enunciação. Parece certo, no entanto, que, mais previsível ou menos previsível, o texto, para se constituir, demanda informação a ser veiculada e, na absoluta maioria das vezes, essa informação decorre da leitura. Estando ausente a leitura, o ato de produção fica comprometido - reiteramos que, entre o input da leitura e o output da produção, há todo um universo sócio-histórico e cultural, no qual se insere o sujeito, que precisa ser considerado.

Assim, professores que não são leitores - e mais: não são leitores de sua área de atuação - estarão aptos para escrever textos nessa mesma área ou tenderão a "não conseguir colocar as idéias no papel"? Caso a origem dessa queixa estivesse tão-somente no comportamento procedimental, bastaria o aprendizado de estratégias formais de organização textual. Um texto, porém, não se faz de superestrutura, entendida como a armação sustentadora do assunto ligada ao gênero, requer também macroestrutura, compreendida como o eixo de significação que constitui o texto (KLEIMAN, 2001), e requer, sobremodo, consideração da relevância à luz da materialidade da enunciação. Para que tal macroestrutura se consolide, importa haver conteúdos potencialmente capazes de serem articulados em um eixo de sentido cuja (re)construção se dê na interlocução.

Isso remete a Charolles (1997) e suas metarregras de coerência. Segundo o autor, para que um texto se constitua como tal, importa haver repetição, de modo a conter, "em seu desenvolvimento linear, elementos de recorrência estrita" (p. 49). Logo, para manter essa continuidade temática há que haver, preliminarmente, domínio sobre o tema. Charolles (1997, p. 58) aponta, ainda, como necessária, a presença da progressão, contraparte da repetição. "Para que um texto seja microestruturalmente ou macroestruturalmente coerente, é preciso que haja no seu desenvolvimento uma contribuição semântica constantemente renovada".

Isso naturalmente supõe uma visão ampla do tema, capaz de viabilizar registro de aspectos relevantes (GRICE, 1975) desse mesmo tema em se tratando do contexto e do interlocutor a que se destina a produção escrita; aqui, novamente os conceitos de situacionalidade e aceitabilidade de Beaugrande e Dressler (1983) e Beaugrande (1997), já referidos. A progressão de que trata Charolles (1997) demanda o cuidado com a relação, ou seja, para que "uma seqüência ou texto sejam coerentes, é preciso que os fatos que se denotam no mundo representado estejam relacionados" (p. 74). Para proceder a tal relação, importa igualmente domínio conceitu- 
al efetivo do tema. Outras questões implicadas no ato da escrita são a intertextualidade de Beaugrande e Dressler (1983) e Beaugrande (1997) e o dialogismo de Bakhtin; Volochinov ([1929] 2002), já que escrever supõe necessariamente visitar escritos de outrem.

Parece certo, pois, que não bastam estratégias procedimentais para dar conta da queixa aqui topicalizada. Se assim fosse, seguramente o ato de escrever seria bastante facilitado para todos porque bastaria o domínio de estratégias superestruturais para tal. Escrever implica, como refere Geraldi (1997), além de estratégias para dizer, ter o que dizer e ter razões para dizer - acrescentaríamos, ter a quem dizer em dado contexto. Isso, em nosso entendimento, remete necessariamente à construção preliminar da informação e à construção preliminar da argumentação, respectivamente, à luz de um universo sócio-histórico e cultural específico. A posse da informação permite-nos dizer; a ciência da propriedade da argumentação faculta-nos razões para dizer, requerendo, para tal, a consideração do processo interlocutivo e das especificidades em que se dá a enunciação. Trata-se, pois, de um processo que passa anteriormente pela leitura entendida como interação dialógica. Inexistindo a leitura, esse processo, em nossa compreensão, fica engessado.

É claro, reconhecemos, há sujeitos conceitual e argumentativamente preparados, mas marcados pela dificuldade de organizar a estruturação textual, normalmente em decorrência de despreparo/inabilidade para síntese, para ordenação lógica do processamento cognitivo de saída da informação ou ineptos para a consideração das particularidades interacionais e de suas demandas. Esses sujeitos certamente teriam suas queixas resolvidas, sob o ponto de vista cognitivo tão-somente, com estratégias de organização textual. Essa, porém, não parece ser a regra nem o caminho mais enriquecedor para o desenvolvimento de tais habilidades.

Em nosso entendimento, a queixa "eu sei o quero dizer, mas consigo colocar no papel” passa, em grande medida, por lacunas informacionais e por desconsiderações interlocutivas - e, por via de conseqüência, argumentativas, considerando que nossos argumentos decorrem, na maioria das vezes, da possibilidade de cotejar informações oriundas de fontes diversas no plano da alteridade; a diversidade das fontes de informação e de interlocutores potenciais permite o posicionamento crítico em detrimento da doutrinação. A queixa concerne igualmente a lacunas lexicais e enunciativas, uma vez que a ampliação da memória lexical e do domínio das formas de estruturação dos enunciados tem como fonte alimentadora a leitura, como registram os PCNs - LP, em alusão inicial nesta 
seção: a leitura, além de alimentar conceitos, alimenta conhecimento formal.

\section{CONSIDERAC̦ÕES FINAIS}

Parece certo que inabilidades docentes para o trato com a leitura e a produção textual tendem a redundar em inabilidades discentes, sobremodo nos contextos socioeconômicos em que a presença da família não dá conta de práticas de letramento que preencham lacunas da formação escolar. Isso remete ao símbolo que Michael Ende usa em seu belíssimo conto "História sem fim": a serpente que engole o rabo. Tratase de uma condição reificada indefinidamente: professores não-leitores não são produtores de texto de fato e, como tal, não podem mediar a formação de leitores e de produtores de texto de fato. Esses não-leitores e não-produtores de texto egressos da escola, tornando-se professores, tendem a repetir o ciclo.

Habituar o outro a ler requer que tenhamos preliminarmente desenvolvido o hábito em nós mesmos - como população, até -, o que demanda necessariamente a convivência com o livro como objeto cotidiano de valor, objeto que vale comprar, tomar emprestado e discutir sobre. Habituar-se em leitura requer educação da capacidade de atenção seletiva, que evita a fuga da concentração por quaisquer razões; requer, também, contato físico com o livro, em todas as instâncias de convivência social; enfim, requer ressignificação do espaço que o livro ocupa nas relações sociais contemporâneas dos brasileiros; isso sem mencionar a escola, território onde o livro deveria ter tratos de majestade plenamente tangível.

A habituação, no entanto, constrói-se a partir da capacidade de entendimento e compreensão do material lido. Não compreender é motivo para não gostar; não gostar é impedimento para habituar-se a. Sob esse ponto de vista, a ação da escola no campo da interpretação de texto ganha lentes de aumento: é preciso ensinar os alunos a compreender, e isso requer exercitação. Se, porém, essa exercitação for desatenta, negligente e descuidada, a capacidade de construir sentidos estará comprometida e, com ela, a possibilidade de habituação em leitura; e mais: com essa impossibilidade de habituação em leitura, fica comprometida também a capacidade de produção textual - a cadeia parece tão evidente quanto preocupante.

Proficiência em produção textual é atividade correlata à leitura. É preciso ter o que dizer para dizer. Normalmente, quando temos o que dizer e a quem dizer, as estratégias procedimentais são itens adicionais 
para potencializar o dito; mas, quando não o temos, tais estratégias tendem a se afigurar como itens redentores para o dito, receitas que simplifiquem o ato e, em boa medida, disfarcem a ausência ou a fragilidade de conteúdo. Trata-se, enfim, de questões tão preocupantes quanto antigas em nossas discussões como nação.

\section{REFERÊNCIAS}

BAGNO, M. A língua de Eulália. São Paulo: Contexto, 1997.

BAGNO, M. Preconceito lingüístico. São Paulo: Loyola, 1999.

BAKHTIN, Michael. Estética da criação verbal. São Paulo: Martins Fontes, 1979/2003.

BAKHTIN, M.; VOLOCHINOV. Marxismo e filosofia da linguagem. São Paulo: Hucitec, 1929/2002.

BARROS, Diana Luz Pessoa de Barros. Semiótica. 3 ed. São Paulo: Ática, 1997.

BEAUGRANDE, R., DRESSLER, W. Introduction to text linguistics. London/New York: Longman, 1983.

BEAUGRANDE, R. New foundation for a science of text and discourse: cognition, communication and freedom of access to knowledge and society. Norwood: New Jersey: Alex, 1997.

BORTONI-RICARDO, Stella Maris. Educação em língua materna. São Paulo: Parábola, 2004.

BRAIT, Beth. Leitura: formas vivas de surpreender significações. In: AGUILERA, Vanderci de Andrade; LÍMOLI, Loredana (Org.). Entrelinhas e entretelas. Londrina: UEL, 2001.

BRASIL. Parâmetros curriculares nacionais. Língua Portuguesa. Secretaria da Educação Fundamental, Brasília, 1997.

BRITTO, Percival Leme. A sombra do caos. Campinas: Mercado das Letras, 2002.

CAGLIARI, Luiz Carlos. Alfabetização e lingüística. São Paulo: Scipione, 2001.

CHAROLLES, Michel. Introduction aux problèmes de la cohèrence des textes. Langue française, Paris, 38, p. 7-41, 1978.

CHAROLLES, Michel. Introdução aos problemas da coerência dos textos. In: GALVES, Charlote, ORLANDI, Eni Pulcinelli, OTONI, Paulo (Org.). O texto: leitura e escrita. Campinas: Pontes, 1997.

COELHO, Nely Novaes. Os contos de fadas. São Paulo: Ática, 1987.

DUCROT, Osvald. Dižer e não dižer: princípios de semântica lingüística. São Paulo: Cultrix, 1972.

ENDE, Michael. História sem fim. 5 ed. São Paulo: Martins Fontes, 1990.

FOUCAMBERT, Jean. A crianç, o professor e a leitura. Porto Alegre: Artes Médicas, 1997.

FREIRE, Paulo. A importância do ato de ler. São Paulo: Cortez, 1982.

GERALDI, João Wanderley. Portos de passagem. 4 ed. São Paulo: Martins Fontes, 1997.

GERALDI, João Wanderley. (Org.). O texto na sala de aula. 3 ed. São Paulo: Ática, 2001.

GRICE, H.P. Logic and conversation. In: COLE, P.; MORGAN, J. (Org.). Syntax and semantics. New York: Speech acts, 1975. v. 3.

KLEIMAN, Ângela. Oficina de leitura. 2 ed. São Paulo: Pontes, 2001.

KOCH, Ingedore V. Introdução à lingüística textual. São Paulo: Martins Fontes, 2004a.

KOCH, Ingedore V. Argumentação e linguagem. 9 ed. São Paulo: Cortez, 2004b.

KOCH, Ingedore V. Desvendando os segredos do texto. 2 ed. São Paulo: Cortez, 2003. 
LUFT, Celso Pedro. Lingua e liberdade. Porto Alegre: LP\&M, 1985.

MARCUSCHI, Luiz A. Lingüistica do texto: o que é e como se faz. Recife: UFPE, 1983.

MORAIS, José. $A$ arte de ler. São Paulo: UNESP, 1996.

MOURA NEVES, Maria Helena de. Gramática na escola. São Paulo: Contexto, 2001.

PERINI, Mário A. Sofrendo a gramática. 3 ed. São Paulo: Ática, 2002.

POSSENTI, Sírio. Por que (não) ensinar gramática na escola. 10 reimpressão. Campinas: Mercado das Letras, 2003.

SOARES, Magda. Linguagem e escola. São Paulo: Ática, 1986.

SANTOS, Caroline C. S. Paixão, desejo e busca: elementos possíveis para uma leitura do livro Ana Z, aonde vai você? Revista de Iniciação Científica da FFC, v. 4, n. 3, 2004.

VYGOSTKY L. S. A formação social da mente. 6 ed. São Paulo: Martins Fontes, 1956/2000.

\section{NOTAS}

${ }^{1}$ Para as finalidades deste artigo, entendemos, para fins operacionais de discussão, Educação Infantil como parte do início do processo de escolarização, ainda que reconheçamos como evidentemente legítimas todas as considerações e textos legais sobre o caráter não-formal e não-escolarizante dessa mesma educação.

${ }^{2}$ Vale, aqui, consideração de natureza análoga à da nota anterior: mantemos o termo alunos por questões de operacionalidade da discussão, mas comungamos com a concepção de que essa designação, a rigor, não se aplica à educação infantil.

${ }^{3}$ Para as finalidades deste estudo, vamos tomar os termos redação/composição/produção textual/textualização como relativos a um mesmo conceito, ainda que estejamos cientes das distinções de amplitude e aporte teórico que cada qual traz. Essa opção decorre do fato de que o enfoque se dá no viés metodológico e não na conceituação em si mesma.

${ }^{4}$ Ou como mote para realização de outras atividades - a leitura pretexto de que trata Geraldi (2001), concebendo pretexto como recurso para tal; o foco da leitura pretexto, a nosso ver, é o exercício de produção textual e não de leitura em si mesma.

${ }^{5}$ Publicações como Luft (1985) com a inserção da crônica O gigolô das palavras, de Luis Fernando Verissimo; Soares (1986); Moura Neves (2001); Possenti (2003?); Perini (2002); Bagno (1997 e 1999); Geraldi (1997 e 2001).

${ }^{6}$ Por variedade padrão, para as finalidades deste estudo, entendemos tratar-se da fala das elites escolarizadas, fala cuja estrutura a escrita procura representar (SOARES, 1986; BAGNO, 1997 e 1999; BORTONI-RICARDO, 2004).

${ }^{7}$ Considerando-se, aqui, como parâmetro, a variedade padrão objeto da atenção escolar.

${ }^{8}$ Fixamo-nos, aqui, na compreensão em detrimento da fruição porque entendemos que fruir, por razões lógicas, dispensa esforços de interpretação e, portanto, não é tópico deste estudo, ainda que requeira, a nosso ver, maiores discussões para que não se processem atividades que costumeiramente vemos nas escolas, as quais trazem consigo a vontade docente de controlar textos artísticos e poéticos, por exemplo, via abordagens formais.

${ }^{9}$ Tais quais interdisciplinaridade, construtivismo, sociointeracionismo, etc.

${ }^{10}$ Não discutiremos; aqui; abordagens psicológicas que tais contos têm suscitado porque esse tipo de comportamento não tem se revelado efetivo nas propostas dos professores participantes deste estudo. 
${ }^{11}$ Ainda que o autor tenha rediscutido essas questões, entendemos procedente sua teorização nessa configuração.

12 "Sabemos, devido a numerosas experiências e observações, que o movimento ocular durante a leitura é um movimento sacádico e não-linear. Isso quer dizer que o leitor eficiente não lê palavra por palavra, seguindo, metaforicamente, o seu dedo na linha. Pelo contrário, os olhos se fixam num lugar do texto (a fixação), para depois pular um trecho (a sacada), e fixar-se num outro ponto mais distante" (KLEIMAN, 2001, p. 33).

Recebido: 25/04/07

Aprovado: 13/09/07

Contato:

Universidade Federal de Santa Catarina - Centro de Comunicação e Expressão

Campus Trindade

Trindade

Florianopolis - SC

BRASIL

E-mail: maryeli@intercorp.com.br 